\title{
Ants' Ability in Solving Simple Problems
}

\author{
Marie-Claire Cammaerts \\ ${ }^{1}$ Département de Biologie des organismes, Faculté des Sciences, Université Libre de Bruxelles, 50, Av F.D. \\ Roosevelt, 1050 Bruxelles, Belgium \\ Correspondence: Marie-Claire Cammaerts, Département de Biologie des organismes, Faculté des Sciences, \\ Université Libre de Bruxelles, Belgium. Tel: 32-2673-4969. E-mail: mccammaerts@gmail.com
}

Received: April 24, 2017

Accepted: May 9, 2017

Online Published: May 12, 2017

doi:10.5539/ijb.v9n3p26

URL: https://doi.org/10.5539/ijb.v9n3p26

\begin{abstract}
Aiming to know the extent of the ants' cognitive abilities, we set Myrmica ruginodis workers in four problematic situations. We discovered that these ants could walk round a barrier, by foraging and navigating as usual, using known visual cues. They could walk preferentially on smooth substrates instead of rough ones, but did not memorize their choice. This behavior may be due to the easier deposit of pheromones on a smooth substrate. The ants could establish a single way when having only two narrow paths for going in and out of their nest. This was the consequence of the ants' traffic and of the distinct pheromonal deposits while going in and out of the nest. The oldest ants needing sugar water could push a door for getting such water. They did so by having the audacity to go on walking, whatever the presence of a door. Such a door is not a tool sensu stricto. Future studies will examine if ants can lean new techniques, can use tools and/or can learn using tools.
\end{abstract}

Key words: barrier, cognition, Myrmica ruginodis, single way, tool

\section{Introduction}

Animals' cognitive ability is a subject of high interest, the animals being vertebrates or invertebrates (Morand-Ferron, Cole, \& Quinn, 2016; Pearce, 2008). The studies deal with associative learning, instrumental conditioning, memorization, navigation, social learning, language, self recognition and consciousness. Among the invertebrates, the bees' cognition (Apis mellifera, Linnaeus 1758) is largely examined, at an ethological and a physiological level (Giurfa, 2013). The studies concern the bees' orientation, navigation, memorization, olfactory and visual conditioning, and brain functioning under stimulation. Ants too are largely studied. They are eusocial and even if their individual behaviors are simple, they collectively accomplish complex tasks. Some of these tasks even resemble those exhibited by highly evolved vertebrates, i.e. nest building, food collection and nest relocation (Pasteels \& Deneubourg, 1987; Hölldobler \& Wilson, 1990; Passera \& Aron, 2005). Ourselves, we have showed that ants recruit nestmates using appropriate pheromones, differently mark their foraging area, nest surroundings, nest entrances, and nest inside, can acquire conditioning, spatial and temporal learning as well as spatio-temporal conditioning, estimate the distance they walked, and navigate using memorized visual and olfactory cues (Cammaerts-Tricot, 1974a; Cammaerts \& Cammaerts, 2000; Cammaerts, 2013a; Cammaerts \& Cammaerts, 2014 and references therein). They even might recognize themselves in a mirror (Cammaerts \& Cammaerts, 2015a), and can expect the location as well as the time of subsequent food delivery on the basis of previous deliveries (Cammaerts \& Cammaerts, 2016a, 2016b). The ontogenesis of some of these abilities has been discovered (Cammaerts \& Cammaerts, 2015). The ants' brain is highly sophisticated and allows performing multiple and complex acts (Strausfeld, 1976). Its center is a group of neuropils, a central complex, allowing integration and coordination (e.g. orientation, navigation). The functioning of the brain is presently investigated in insects with broad behavioral repertories (Pfeiffer \& Homberg, 2014). If some researchers point out the ants' sophisticated behavior, other ones explain their complex tasks by mathematical models and statistical reasoning. This occurs, for instance, for the ants' cemeteries organization (Theraulaz et al., 2002; Martin, Chopard \& Albuquerque, 2002). To define the extent of the ants' cognitive abilities, we should successively answer to the following questions. Which ants' behaviors are the mathematical consequences of numerous simple acts? Which ones result from conditioning or imitation? What can ants effectively do by themselves, spontaneously, without having been progressively conditioned? In the present work, we try to answer the first question; following works will deal with the two other questions (see the end of the 'Discussion' section). Here, we set ants in four problematic situations requiring, at first sight, cognitive abilities. We examined if ants could walk round a barrier, use smooth paths instead of rough 
ones, establish a single way for making their traffic easier, and push a door for getting to their sugar water supply. These four situations may occur on field. An obstacle may be suddenly present on the ants' path; some paths may become uncomfortable; some paths may become very narrow; some elements (i.e. a leave, grass) may be found in front of the nest entrance. We worked on Myrmica ruginodis Nylander, 1846, a species we have largely studied. We know its eye morphology (140 ommatidia), subtended angle of vision $\left(3^{\circ} 10^{\prime}\right)$, visual perception (the workers can even distinguish different patterns of small luminous spots located above them), navigation system (the species uses visual cues, and uses odors only when visual cues are absent), visual and olfactory conditioning (the latter conditioning can be acquired only in darkness), recruitment strategy (Cammaerts \& Cammaerts, 2014), and spatio-temporal learning capability (Cammaerts, 2013a).

Thus, for going on researching, in successive experimental steps, about the nature and the extent of ants' cognition, we firstly tested here ants of a known species in four problematic situations and observed if and how they solved the problem.

\section{Material and Methods}

\subsection{Collection and Maintenance of Ants}

The experiments were made on four colonies of M. ruginodis collected in the Aise Valley (Ardenne, Belgium) in June 2016. The ants nested under stones; the colonies contained 500-800 workers, $1-2$ queens and brood. They were maintained in the laboratory in artificial nests made of $1-3$ glass tubes half filled with water, a cotton plug separating the ants from the water. The tubes were deposited in a tray $(34 \mathrm{~cm} \times 23 \mathrm{~cm} \times 4 \mathrm{~cm})$, the internal sides of which were slightly covered with talc. The trays served as foraging areas and food was delivered in them. This food consisted of an aqueous solution of sugar provided ad libitum in a small glass tube (diameter: $1.5 \mathrm{~cm}$, length: $7 \mathrm{~cm}$ ) plugged with cotton, and of pieces of Tenebrio molitor larvae (Linnaeus, 1758) provided three times a week on a glass slide. Laboratory temperature was $18^{\circ} \mathrm{C}-22^{\circ} \mathrm{C}$, the relative humidity circa $80 \%$. Lighting had an intensity of 330 lux while caring of the ants and testing them. During other time periods, it was provided by natural light through a window, and varied from 5 to 120 lux. The electromagnetic field had an intensity of $2-3 \mu \mathrm{W} / \mathrm{m}^{2}$. The members of a colony are here termed nestmates, as is commonly done for social hymenoptera.

\subsection{Experimental Apparatus and Assessment of the Ants' Behavior}
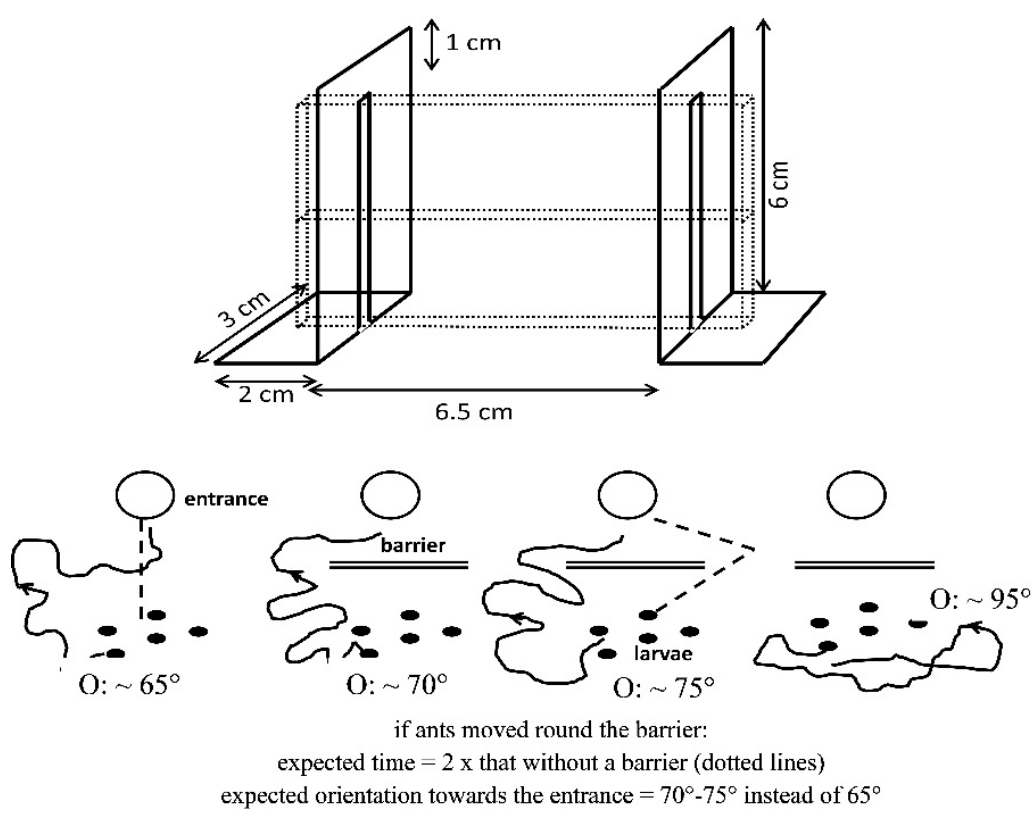

Figure 1. Upper part: experimental apparatus allowing setting a barrier between the nest entrance and larvae + workers removed from the nest. The ants should walk round the barrier for replacing the larvae in the nest. The drawn paths with an arrow represent ants' trajectories; the dotted lines schematize the time taken for reaching the entrance. Lower part: assessment of the potential ants' behavior in the absence or the presence of a barrier 


\subsubsection{Preliminary Comments}

Ants were submitted to artificial situations they had never experienced before. Indeed, if they had already lived these situations, they may have already acquired, by conditioning, the adequate behavior, and we should no longer be able to appreciate their cognition. The observations were made at the social level. The assessments were made on individuals but individual responses were not examined. The tested ants were the foragers moving on the foraging area, and the ants staying at the nest entrances. About 25 ants of each colony, thus a total of 100 ants, interacted with the provided apparatus.

The experiments were made from the end of May until the beginning of September 2016, i.e. during 3 months. The time period between two experiments made on a given colony equaled $3 / 4$ month, what corresponds for humans to 22.5 months (=1 year 5/6). Such a time period allowed avoiding any influence of an experiment on the following one. Moreover, the obtained results provided another reason, explained in $\mathbf{4}$, for stating that the ants' behavior in the course of an experiment has not been influenced by possible acquired behavior during a previous experiment.

The experiments were made after the emergences occurring in spring and before those occurring in autumn. The four colonies were demographically similar. However, we observed constant differences between the four colonies as for their cognitive abilities. This important point was specifically studied, making additional experiences, and has been published (Cammaerts, 2017).

Except for the first experiment, during which we repeated one assessment, each time we made again an experiment, we in fact analyzed another element (for instance the learning of an adequate behavior).

\subsubsection{Can Ants Walk Round a Barrier?}

Each colony had its own apparatus that formed a barrier on the ants' trajectories. Two glass slides $(7.5 \mathrm{~cm}$ x $2.5 \mathrm{~cm}$ x $1 \mathrm{~mm}$ ) were inserted one above the other in two stands, each one made of a piece of strong white paper (Steinbach ${ }^{\circledR}, 8 \mathrm{~cm} \times 3 \mathrm{~cm}$ ) folded orthogonally in order to present an horizontal part $(2 \mathrm{~cm} \times 3 \mathrm{~cm})$ and a vertical one $(6 \mathrm{~cm} \times 3 \mathrm{~cm})$. The horizontal part of each stand was oriented towards the outside of the apparatus. The vertical parts were vertically pierced in their middle, from the bottom up to $5 \mathrm{~cm}$ height. The two glass slides were inserted one above the other in the two obtained slits (Figure 1).

In the first phase, more than 10 larvae and workers were removed from their nest in the absence of a barrier, and a first, control, assessment was conducted. In the second phase, an apparatus was set $3 \mathrm{~cm}$ in front of the nest entrance, and more than 10 larvae and workers were removed from the nest and deposited on the foraging area lying in front of the barrier on the side not facing the entrance. A second assessment was then conducted. After that, in the third phase, a second experiment similar to the latter one was performed and a third assessment was made for examining if ants could ameliorate their performance. Each time, two kinds of assessment were made in the course of two successive experiments: one for the time taken by the ants for replacing 10 larvae in the nest, and one for the ants' orientation towards their nest entrance. An experiment without and then with a barrier was made on a given colony on the same day. The larvae were in a similar physiological state in the course of the two experiments

To assess the time taken by the ants for replacing the larvae in the nest, the time elapsed since the start of the experiment was noted when 1, 2, $3 \ldots 10$ larvae were replaced. Theoretically, in presence of a barrier, if ants walked round it, the time they took for replacing 10 larvae in the nest would be maximally twice the time they took in the absence of a barrier (Figure 1). The values of that elapsed time obtained during the control and the two test assessments were compared to one another using the non-parametric Wilcoxon test (Siegel \& Castellan, 1989).

To assess the ants' orientation towards the nest entrance, the trajectories of 10 ants from each of the four colonies $(\mathrm{n}=40)$ were recorded on a glass slide, and copied on transparent polyvinyl sheets. These sheets remained affixed to a PC monitor screen due to their static electricity charge. The trajectories were analyzed using specifically designed software (Cammaerts, Morel, Martino \& Warzée, 2012a). Each trajectory was entered in the software by clicking on it every $5 \mathrm{~mm}$ with the mouse and then entering the location of the nest entrance. After that, the total time of the trajectory was entered, and the software was asked to calculate the ant's orientation towards the entrance. This orientation $(\mathrm{O}$, measured in angular degrees) was the sum of the angles, measured at each successive point of the trajectory, made by each segment 'point $i$ of the trajectory - entrance' and each segment

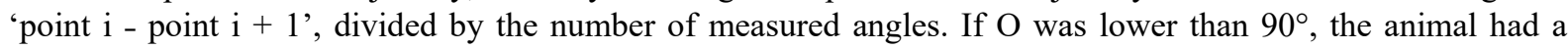
tendency to orient itself towards the entrance; if $\mathrm{O}$ was larger than $90^{\circ}$, the animal had a tendency to avoid the entrance. Theoretically, the ants' orientation towards the entrance would be less than $90^{\circ}$ in the absence of a barrier, and of lower quality in the presence of a barrier. The orientation of theoretical trajectories was assessed. An orientation of about $65^{\circ}$ was found for ants moving to the entrance in the absence of a barrier, of about $70^{\circ}$ for ants doing so walking efficiently round a barrier, of about $75^{\circ}$ for ants wanting to move to the entrance but walking 
badly round the barrier, and of about $95^{\circ}$ for ants unable to walk round the barrier (Figure 1). Each distribution of 40 values was characterized by its median and quartiles, and control and test distributions were compared using the non-parametric $\chi^{2}$ test (Siegel \& Castellan, 1989).
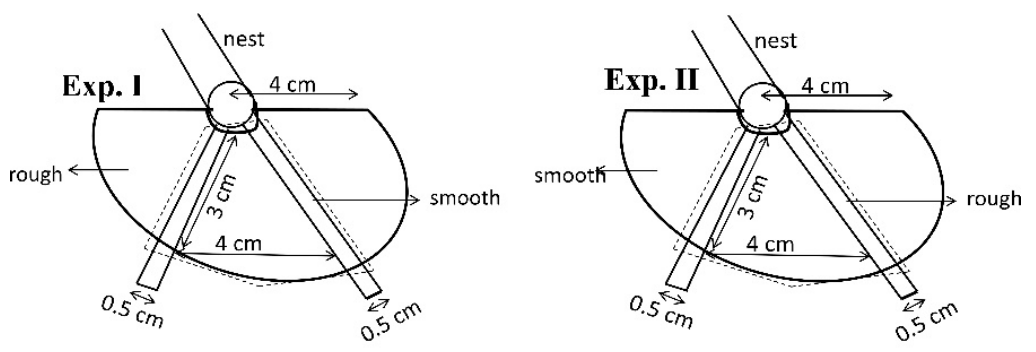

if ants cqually used the two kinds of substrate:

Exp. I: $\mathrm{n}^{\circ} \mathrm{s} \times 2.5=\mathrm{n}^{\circ} \mathrm{r}$; Exp. II: $\mathrm{n}^{\circ} \mathrm{s}=\mathrm{n}^{\circ} \mathrm{r} \times 2.5$ if they preferentially used the smooth paths:

Exp. I: $\mathrm{n}^{\circ} \mathrm{s} \times 2.5>\mathrm{n}^{\circ} \mathrm{r}$; Exp. II: $\mathrm{n}^{\circ} \mathrm{s}>\mathrm{n}^{\circ} \mathrm{r} \times 2.5$

Figure 2. Schema of the apparatus used for examining if ants could select smooth paths instead of rough ones. The apparatus was made of narrow smooth paths and a large rough one (Exp. I) or of a large smooth path and narrow rough ones (Exp. II), and was set just at the nest entrance. The dotted lines demarcate the observed area on which ants were counted ( $\mathrm{n}^{\circ} \mathrm{s}=$ number on the smooth paths; $\mathrm{n}^{\circ} \mathrm{r}=$ number on the rough paths). The reasoning allowing assessing the ants' use of the smooth paths is summarized below the drawing

\subsubsection{Can Ants Select Smooth Paths Preferably to Rough Ones?}

Two kinds of apparatus were used, an apparatus of each kind being constructed for each of the four colonies. The first kind consisted of a half circle of abrasive paper (emery $\mathrm{n}^{\circ} 280$, diameter $=4 \mathrm{~cm}$ ), with a half-circular notch (diameter $=1.2 \mathrm{~cm}$ ) in its center, and of two linear pieces of smooth extra strong white paper (smooth substrate, Steinbach ${ }^{2}, 0.5 \mathrm{~cm} \mathrm{x} 4 \mathrm{~cm}$ ) deposited on the abrasive paper, each one along a radius, the angle between the two radii equaling approximately $80^{\circ}$. The second kind was identical to the first one except that the half circle was made of smooth paper and the two linear parts of rough paper (Figure 2).

To perform a handling on a colony, an experimental apparatus was set in front of the nest entrance, with the notch of the apparatus touching the entrance. Ants and larvae were removed from the nest and deposited beyond the abrasive paper. The ants had to cross a space $3 \mathrm{~cm}$ long to enter and exit their nest, moving on the abrasive and/or the smooth substrate. The ants moving on the rough substrate $\left(n^{\circ} r\right)$ and on the smooth one $\left(n^{\circ} s\right)$ were counted each $30 \mathrm{~s}$ for 10 minutes, and the numbers obtained during the first five and the last five minutes were separately added. One day later, a second handling was done for examining if ants had retained something from their previous experience. For the first kind of apparatus, the surface of the rough substrate was 2.5 times larger than the surface of the smooth ones. For the second kind of apparatus, the surface of the smooth substrate was 2.5 times larger than the surface of the rough ones (Figure 2). Therefore, $\mathrm{n}^{\circ} \mathrm{s} \times 2.5 / \mathrm{n}^{\circ} \mathrm{r}$, as well as $\mathrm{n}^{\circ} \mathrm{s} / \mathrm{n}^{\circ} \mathrm{r} \times 2.5$ quantified the ants' choice of the smooth substrate during the first and the second experiment respectively. Statistically, if ants equally walked on the two kinds of substrate, $n^{\circ} \mathrm{s} \times 2.5$ and $\mathrm{n}^{\circ} \mathrm{r}$, as well as $\mathrm{n}^{\circ} \mathrm{s}$ and $\mathrm{n}^{\circ} \mathrm{r} \times 2.5$, for the first as well as the second experiment respectively, would not differ from the numbers (e) expected if ants randomly walked on the two substrates. They were thus statistically compared to these random numbers using the non-parametric $\chi^{2}$ test for 2 x 2 contingency tables (Siegel \& Castellan, 1989).

\subsubsection{Can Ants Establish a Single Way for Making their Traffic Easier?}

An apparatus was constructed for each colony. It consisted of a piece of extra strong white paper (Steinbach ${ }^{\circledR}$ ) made of a circular part (diameter: $1.1 \mathrm{~cm})$ with a rectangular hole $(4 \mathrm{~mm} \times 2 \mathrm{~mm})$ and of two linear paths $(4 \mathrm{~cm} \mathrm{x}$ $2 \mathrm{~mm}$ ), one oriented to the left, the other to the right of the circular part (Figure 3). The linear paths were too narrow to accommodate two ants walking side by side; they could only walk one behind the other, and consequently not in opposite directions.

To perform an experiment on a colony, approximately 10 ants and larvae were removed from the nest and deposited in front of it at a distance of $6 \mathrm{~cm}$. Then, the circular part of an apparatus was inserted in the nest entrance, which thus became limited to the hole in the circular part of the apparatus now standing vertically. The two linear 
parts of the apparatus were lying on the foraging area in front of the entrance. Just after that, the ants walking on the left and the right linear parts of the apparatus, and going towards or away from the nest entrance, were counted each $30 \mathrm{sec}$ during 10 minutes. The numbers obtained during the first five and the last five minutes were separately added for each colony, and the mean values for the four colonies were established. These final values were compared to those expected if ants moved towards or away from the nest entrance, equally walking on the left and right linear parts of the apparatus, using the non-parametric goodness of fit $\chi^{2}$ test (Siegel \& Castellan, 1989). A variable assessing the ants' establishment of a single way was set up: $\mathrm{n}^{\circ}$ ants moving 'in' on the left path $/ \mathrm{n}^{\circ}$ ants moving 'out' on the left path $\mathrm{X}{ }^{\circ}$ ants moving 'out' on the right path $/ \mathrm{n}^{\circ}$ ants moving 'in' on the right path.

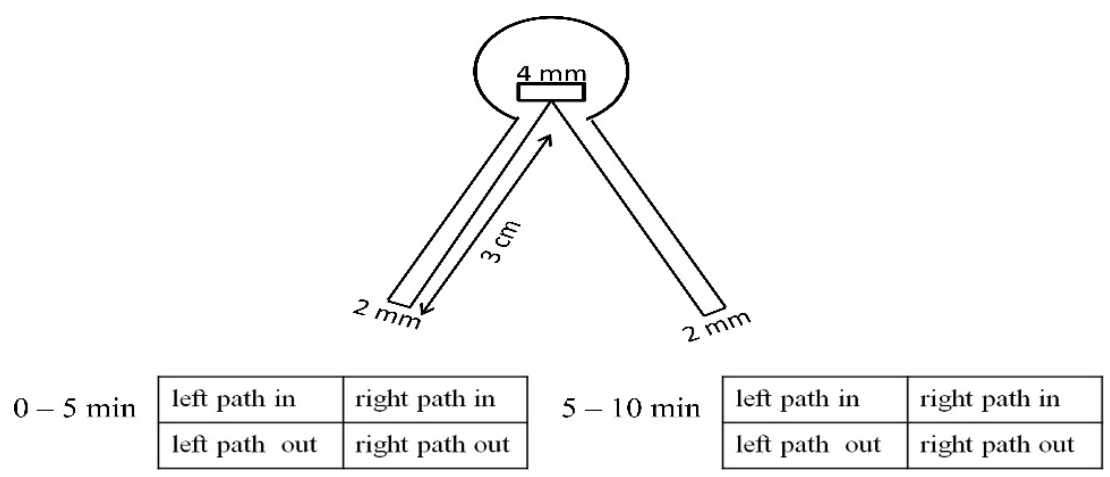

Figure 3. Schema of the apparatus used for examining if ants could establish a single way. The apparatus shut the nest entrance, but yet provided an access hole (for only two ants), and had two access paths too narrow for two ants walking side by side. The assessment of the ants' traffic on the two paths is summarized under the schema

\subsubsection{Can Ants Push a Door for Getting to their Sugar Water?}

An apparatus was built for each colony. A tube of the type used for providing sugar water to the ants was closed off with transparent polyvinyl. To do so, an adequate piece of polyvinyl was cut; this piece was made of an upper rectangular part $(2.5 \mathrm{~cm} \times 1 \mathrm{~cm})$ and a lower circular one (diameter $=1.5 \mathrm{~cm})$. The upper part was attached (using Sellotape $($ ) ) to the tube containing sugar water, just above its entrance, and the lower part of the polyvinyl piece hung just in front of the entrance (Figure 4). The entrance was entirely though weakly closed. Consequently, the ants could not walk up to the sugar water but had to push the lower circular part of the polyvinyl piece (i.e., the door) in order to reach the sugar water, or more exactly the cotton plugging the tube. The ants recognized their usual feeder, and guessed it contained sugar water.

For conducting the experiment, the usual tubes containing sugar water were removed from the ants' foraging area, and one day later, at a time when the ants wanted to drink, an experimental feeding apparatus was set in each foraging area. Since that time, the numbers of ants drinking the sugar water, after having pushed the door, were recorded every 5 minutes, during one hour, for each colony, and the mean value of the $48(12 \times 4)$ counts was established. The ants' behavior in front of the experimental feeder was also observed during each counting.

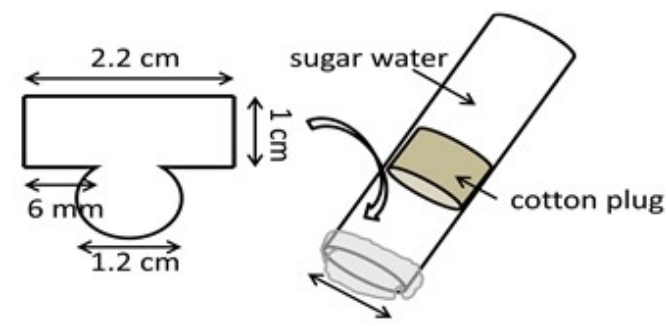

Figure 4. Schema of the apparatus used for examining if ants could push a door for accessing their sugar water supply. The 'door' (left drawing) was made of thin polyvinyl. The upper rectangular part was tied to the tube containing the sugar water, and the lower circular part closed off the entrance. The ants reaching the cotton plug and having thus pushed the door were counted every 5 minutes during one hour 


\section{Results}

\subsection{Can Ants Walk Round a Barrier?}

Table 1. Ants' walking round a barrier.

\begin{tabular}{|c|c|c|c|c|c|c|c|c|c|c|}
\hline \multirow{2}{*}{ Experiment variables } & \multicolumn{5}{|c|}{ without barrier } & \multicolumn{5}{|c|}{ with a barrier } \\
\hline & A & $\mathrm{B}$ & $\mathrm{C}$ & $\mathrm{D}$ & mean & A & B & $\mathrm{C}$ & $\mathrm{D}$ & mean \\
\hline \multicolumn{11}{|l|}{ First } \\
\hline time for re-entering 10 larvae (seconds) & 240 & 600 & 450 & 390 & 420 & 420 & 1,800 & 600 & 540 & 848 \\
\hline orientation to the nest (angular degrees) & 67 & 81 & 75 & 73 & 73 & 70 & 90 & 85 & 79 & 81 \\
\hline \multicolumn{11}{|l|}{ Second } \\
\hline time for re-entering 10 larvae (seconds) & & & & & & 180 & 470 & 290 & 330 & 318 \\
\hline orientation to the nest (angular degrees) & & & & & & 68 & 86 & 79 & 76 & 77 \\
\hline
\end{tabular}

A barrier was set in front of the nest entrance of four colonies (A, B, C, D). Workers and larvae were removed from the nest. The time the ants took for re-entering 10 larvae and the ants' orientation towards the entrance were assessed. Ants effectively walked round the barrier.

An experiment without a barrier, then with a barrier was made on a given colony on the same day. The larvae had the same weight during the two kinds of experiments, and the time taken each time by the ants for replacing ten larvae in the nest could be compared.

Without a barrier, the ants soon re-entered the 10 larvae (mean: $420 \mathrm{sec}$ ), orientating themselves towards the entrance (73.1 ang. deg.) (Tab. 1). When ants were confronted to a barrier for the first time, they hesitated a moment, then went to the right or the left of the barrier and most of them succeeded in walking round the barrier. The time spent for re-entering the larvae meanly equaled $848 \mathrm{sec}$, what was the time expected if the ants correctly walked round the barrier. The ants' orientation towards the entrance in presence of a barrier meanly equaled 81.4 ang deg., what was nearly the value expected if ants duly walked round the barrier (Tab. 1). Ants succeeded thus, with some delay, in walking round a barrier set on their way (Figure 2A). Could they become more performing if confronted a second time to the same situation?

During a second experiment, the ants more promptly walked round the barrier, more quickly re-entered the larvae, and slightly better oriented themselves towards the entrance. The difference of time taken for re-entering the larvae between the second and the first confrontations with a barrier was significant: $\mathrm{N}=10, \mathrm{~T}=-55, \mathrm{P}=0.001$. The difference of orientation $\left(\mathrm{O}=77\right.$ instead of 81 angular degrees) was not significant $\left(\chi^{2}=0.91, \mathrm{df}=3\right.$, NS). However, it was obvious that ants learned that a barrier may be present on their way, and that they had to walk round it.

Let us precise that the species' trail pheromone is rather volatile and persists only for $10 \mathrm{~min}$. The ants have thus not followed some previously deposited trail, but have really memorized an adequate behavior.

\subsection{Can Ants Select Smooth Paths Preferably to Rough Ones?}

In presence of either the first or the second kind of apparatus, ants moved proportionally more often on the smooth paths than on the rough ones after a delay of some five minutes (Tab. 2, Figure 2D, E)). With the first kind of apparatus, during the first handling, the numbers of ants walking on the smooth paths on one hand and on the rough substrate on the other hand did not statistically differ from those expected if ants randomly moved on the two substrates during the first five minutes of the experiment ( $\left.39.4 v s 23 ; \chi^{2}=0.51, \mathrm{df}=1, \mathrm{NS}\right)$ while they statistically differed during the five last minutes $\left(35 v s 11 ; \chi^{2}=5.65, \mathrm{df}=1, \mathrm{P}<0.02\right)$. During the second handling, these ants' numbers again did not statistically differ during the first five minutes ( $\left.33 v s 18 ; \chi^{2}=1.67, \mathrm{df}=1, \mathrm{NS}\right)$ and slightly differed during the five last minutes ( $\left.31 v s 11 ; \chi^{2}=4.09, \mathrm{df}=1, \mathrm{P}<0.05\right)$. With the second kind of apparatus, during the first handling, the numbers of ants moving on the smooth and the rough substrates did not statistically differ from the random ones during the first five minutes $\left(\chi^{2}=0.54, \mathrm{df}=1, \mathrm{NS}\right)$ while they differed during the last five minutes $\left(\chi^{2}=4.24, \mathrm{df}=1, \mathrm{P}<0.05\right)$. During the second handling, again, the difference between obtained and random results was not significant for the first five minutes $\left(\chi^{2}=0.91, \mathrm{df}=1, \mathrm{NS}\right)$, and significant for the last five minutes $\left(\chi^{2}=5.38, \mathrm{df}=1, \mathrm{P}<0.02\right)$. 
For each kind of apparatus, comparing the first and the last five minutes of each handling allows deducing that ants delayed in using the smooth paths. For each kind of experiment, comparing the first and the second handling allows deducing that ants retained nothing from their first experience. They still progressively used the smooth paths during the second handling just like they did during the first one. The here above problem (select the more adequate path) differs from the previous one (walking round a barrier), requires in fact more implication of the individuals, and ants appeared to solve the problem with some more difficulty.

Table 2. Ants' using smooth paths preferentially to rough ones

\begin{tabular}{|c|c|c|c|c|c|c|}
\hline \multirow{2}{*}{\multicolumn{2}{|c|}{ Experiment, handling and time }} & \multicolumn{4}{|c|}{$\begin{array}{l}\text { Values of the variable assessing the choice of the smooth substrates } \\
\text { by colonies }\end{array}$} & \multirow[t]{2}{*}{ Mean and statistical results } \\
\hline & & $\mathrm{A}$ & $\mathrm{B}$ & $\mathrm{C}$ & $\mathrm{D}$ & \\
\hline \multirow[t]{4}{*}{ I 1} & $0^{\prime}-5^{\prime}$ & $20 \times 2.5 / 17$ & $12 \times 2.5 / 21$ & $20 \times 2.5 / 36$ & $11 \times 2.5 / 18$ & $15.75 \times 2.5 / 23$ \\
\hline & & $=2.94$ & $=1.45$ & $=1.40$ & $=1.53$ & $=1.71 ; \mathrm{NS}$ \\
\hline & $5^{\prime}-10^{\prime}$ & $13 \times 2.5 / 2$ & $13 \times 2.5 / 14$ & $17 \times 2.5 / 17$ & $13 \times 2.5 / 9$ & $14 \times 2.5 / 10.5$ \\
\hline & & $=16.25$ & $=2.32$ & $=2.50$ & $=3.61$ & $=3.33 ; \mathrm{S}$ \\
\hline \multirow[t]{4}{*}{ I 2} & $0^{\prime}-5^{\prime}$ & $15 \times 2.5 / 13$ & $11 \times 2.5 / 20$ & $15 \times 2.5 / 27$ & $12 \times 2.5 / 13$ & $13.25 \times 2.5 / 18$ \\
\hline & & $=2.88$ & $=1.38$ & $=1.39$ & $=2.31$ & $=1.81 ; \mathrm{NS}$ \\
\hline & $5^{\prime}-10^{\prime}$ & $10 \times 2.5 / 4$ & $13 \times 2.5 / 16$ & $14 \times 2.5 / 15$ & $13 \times 2.5 / 8$ & $12.5 \times 2.5 / 10.8$ \\
\hline & & $=6.25$ & $=2.03$ & $=2.33$ & $=4.06$ & $=2.89 ; \mathrm{S}$ \\
\hline \multirow[t]{4}{*}{ II 1} & $0^{\prime}-5^{\prime}$ & $22 / 4 \times 2.5$ & $18 / 3 \times 2.5$ & $19 / 6 \times 2.5$ & $29 / 8 \times 2.5$ & $20.75 / 5.25 \times 2.5$ \\
\hline & & $=2.20$ & $=2.50$ & $=1.27$ & $=1.20$ & $=1.58 ; \mathrm{NS}$ \\
\hline & $5^{\prime}-10^{\prime}$ & $32 / 4 \times 2.5$ & $22 / 2 \times 2.5$ & $22 / 2 \times 2.5$ & $17 / 2 \times 2.5$ & $23.25 / 2.5 \times 2.5$ \\
\hline & & $=3.20$ & $=4.40$ & $=4.40$ & $=3.40$ & $=3.72 ; \mathrm{S}$ \\
\hline \multirow[t]{4}{*}{ II 2} & $0^{\prime}-5^{\prime}$ & $20 / 3 \times 2.5$ & $13 / 2 \times 2.5$ & $26 / 4 \times 2.5$ & $15 / 3 \times 2.5$ & $18.75 / 4 \times 2.5$ \\
\hline & & $=2.67$ & $=2.60$ & $=2.60$ & $=2.00$ & $=1.48 ; \mathrm{NS}$ \\
\hline & $5^{\prime}-10^{\prime}$ & $37 / 2 \times 2.5$ & $21 / 3 \times 2.5$ & $36 / 6 \times 2.5$ & $22 / 3 \times 2.5$ & $29 / 3.5 \times 2.5$ \\
\hline & & $=7.40$ & $=2.80$ & $=2.50$ & $=2.93$ & $=3.31 ; \mathrm{S}$ \\
\hline
\end{tabular}

An apparatus made of a rough and a smooth substrate was set in front the nest entrance. The ants walking on each substrate were counted in the course of time. The variables: $n^{\circ}$ on the smooth paths $x 2.5 / \mathrm{n}^{\circ}$ on the rough path (Exp. I), and $\mathrm{n}^{\circ}$ on the smooth path $/ \mathrm{n}^{\circ}$ of the rough ones $\mathrm{x} 2.5$ (Exp. II) assessed the ants' choice of the smooth paths. Each experiment comprised two handlings $(1,2)$. Each time, the mean results were statistically analyzed. The ants walked, with delay, on the smooth paths, but retained nothing from their first experience. NS and S: not significant and significant difference with $\mathrm{P}=0.05$.

Table 3. Ants' establishment of a single way

\begin{tabular}{|c|c|c|c|c|c|c|c|c|c|c|}
\hline \multirow{2}{*}{$\begin{array}{c}\text { Paths } \\
\text { directions }\end{array}$} & \multicolumn{2}{|c|}{ colony A } & \multicolumn{2}{|c|}{ colony B } & \multicolumn{2}{|c|}{ colony $\mathrm{C}$} & \multicolumn{2}{|c|}{ colony D } & \multicolumn{2}{|r|}{ Sums } \\
\hline & $0^{\prime}-5^{\prime}$ & $5^{\prime}-10^{\prime}$ & $0^{\prime}-5^{\prime}$ & $5^{\prime}-10^{\prime}$ & $0^{\prime}-5^{\prime}$ & $5^{\prime}-10^{\prime}$ & $0^{\prime}-5^{\prime}$ & $5^{\prime}-10^{\prime}$ & $0^{\prime}-5^{\prime}$ & $5^{\prime}-10^{\prime}$ \\
\hline Left & 12 & 6 & 7 & 6 & 9 & 9 & 6 & 6 & 34 & 27 \\
\hline out & 3 & 3 & 5 & 0 & 4 & 2 & 3 & 3 & 15 & 8 \\
\hline \multirow{2}{*}{$\begin{array}{l}\text { right in } \\
\text { out }\end{array}$} & 1 & 2 & 4 & 2 & 2 & 4 & 3 & 2 & 10 & 10 \\
\hline & 9 & 8 & 6 & 4 & 7 & 4 & 8 & 10 & 30 & 26 \\
\hline Statistics $\chi^{2}$ & & & & & & & & & 17.20 & 16.89 \\
\hline df & & & & & & & & & 1 & 1 \\
\hline $\mathrm{P}$ & & & & & & & & & $<0.001$ & $<0.001$ \\
\hline
\end{tabular}

An apparatus inserted in the nest entrance allowed ants going in and out of the nest moving only on a left and right narrow path. Ants moving in and out of the nest on each of these two paths were counted in the course of time, the obtained numbers being then pooled after $5 \min \left(0^{\prime}-5^{\prime}\right)$ and $10 \min \left(5^{\prime}-10^{\prime}\right)$. The ants moved 'in' on the left path, and 'out' on the right path within 5 min. 


\subsection{Can Ants Establish a Single Way for Making their Traffic Easier?}

The ants established a single way in a few minutes when they had only two narrow paths for coming in and out of their nest (Figure 2B). This occurred more or less accurately and rather rapidly for each colony (Tab. 3). Firstly, the variable assessing the ants' establishment of a single way equaled 17.0, 4.3, 5.5 and 7.2 for colonies A, B, C and D respectively, and meanly 8.5 what was larger than 1 , the value expected if ants could not establish a single way. Secondly, the total numbers of ants moving in and out of the nest on the left and the right narrow paths statistically already differed during the first five minutes (for the first five minutes: $34,15,10,30$ respectively, $\chi^{2}=17.20$, $\mathrm{df}=$ $1, \mathrm{P}<0.001$; for the last five minutes: $27,8,10,26$ respectively, $\left.\chi^{2}=16.89, \mathrm{df}=1, \mathrm{P}<0.001\right)$. The ants established thus a single way in about three minutes. This result is explained in $\mathbf{4}$.

\subsection{Can Ants Push a Door for Getting their Sugar Water?}

In front of the experimental apparatus, the ants stopped, turned all around, and tried to enter the tube. Two-thirds of them moved away. One-third succeeded in pushing the polyvinyl door; they entered the tube and drank sugar water (Figure 2C). In the course of 12 counting, 15, 3, 8, and 14 such ants were seen for colonies A, B, C and D respectively. Forty ants were thus counted in 12 counts on 4 colonies $(n=48$ counts). At a given time, meanly 0.83 ants were thus drinking the sugar water beyond the door. About $1 / 3$ of the foragers had thus the audacity (instead of the true cognitive ability) of pushing the polyvinyl door. Note that such a door was not a tool sensu stricto, though perhaps at the limit of being one. The foragers having pushed the door were old and in need of drinking sugar water. Indeed, when they went out of the small tube, their gaster had enlarged, what proved that they had drunk a large amount.

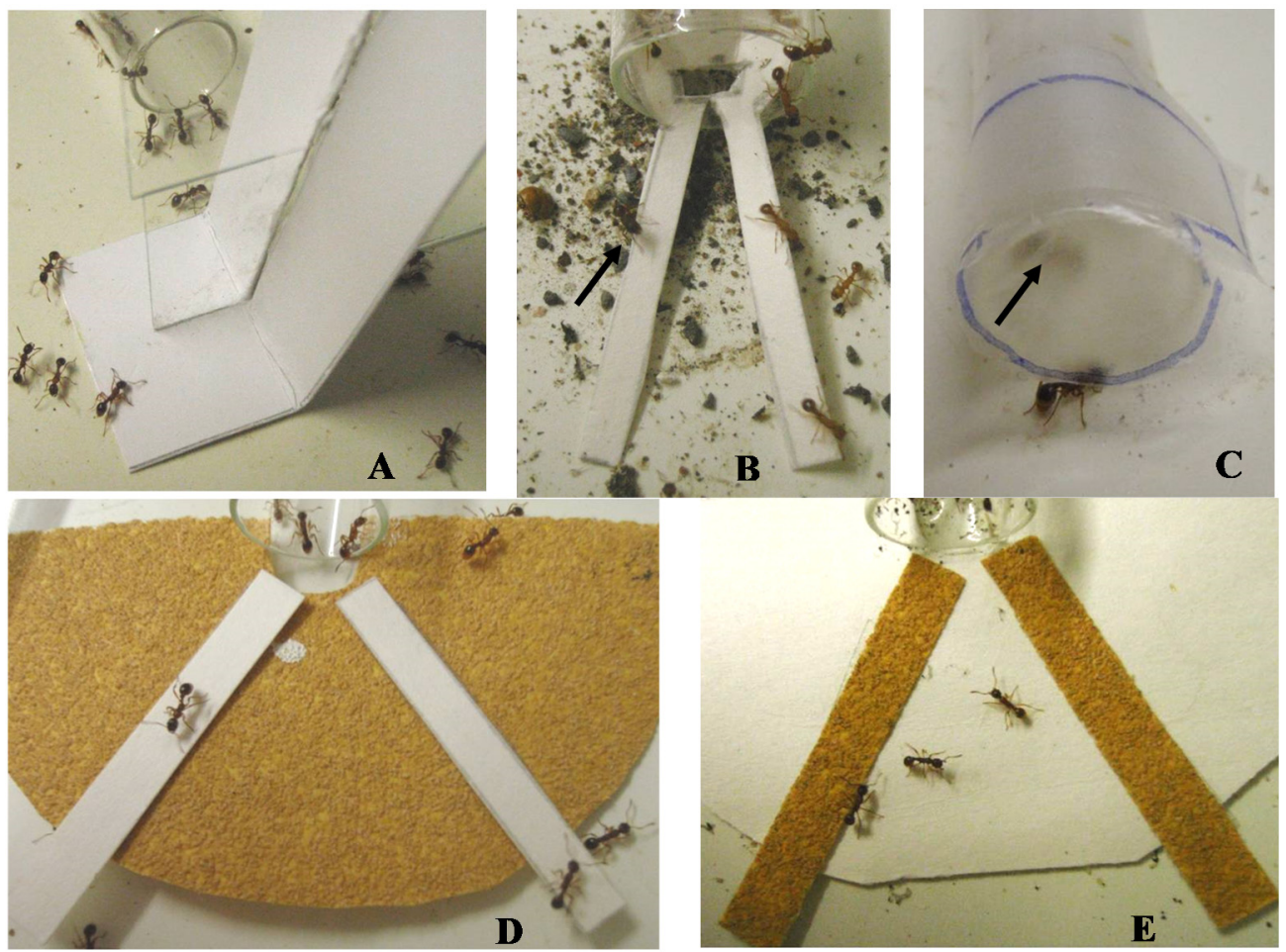

Figure 6. Some views of the experiments. A: ants walking round a barrier. B: two ants going out of their nest by moving on the right access path, and one ant in the process of entering, on the left access path (arrow). $\mathbf{C}$ : an ant going out of its feeding tube after having drunk (its gaster is enlarged), while another ant (arrow) can be guessed being drinking inside the tube, behind the polyvinyl sheet; the two ants have pushed the door closing the tube. D, E:

ants walking essentially on smooth substrates instead of on rough ones for accessing their nest entrance

\section{Discussion}

We aimed to go some steps further in our study of ants' cognition and to approach the extent of their cognition. We found that M. ruginodis workers could walk round a barrier, could with some delay preferably move on smooth substrates instead of on rough ones but did not memorize their experience, could establish a single way for making 
their traffic easier, and could push a door for reaching their sugar water. Such a door was not a tool. Thus, as long as the use of a sensu stricto tool is not required, the ants may be able to find the solution. Future works will examine the ants' behavior when the use of novel techniques will be required, then when they will have to use simple tools.

An experiment here performed on ants had no influence on a subsequent one. The ants' score was excellent in the course of the first kind of experiment, of good quality during the second kind, of middle quality in the third one and of poor quality in the fourth one. If an experiment had influenced the ants' behavior in the course of a following one, the ants' score would have increased all along the experimental work.

Below, we summarize information about collective intelligence, we try to explain our results on the basis of this information, of personal and other researchers' observations, and of what we know about the biology of $M$. ruginodis. After that, we emit a general comment about our work and the subject in general, and we announce our future works, before concluding.

In comparison with other animals, ants have a large behavioral repertory and numerous cognitive capabilities. However, their repertory and cognition are not excessively developed (Dornhaus \& Franks, 2008). Ants efficiently communicate between them and imitation is possible between young and old workers. Again, concerning these two traits, limits exist (Dornhaus \& Franks, 2008). Each social individual can perform few tasks by itself, while the entire colony can make many and complex tasks (Marsan, Simaon, Lavens, Chapelle, Saint Girons et al., 2014). In any animal colony, complex behavior and solving problems emerge from individuals' simple behavior (Jeanson, Deneubourg, Grimal, Theraulaz, 2004). For example, ants can build adequate and sophisticated nests working all together, each individual performing only simple tasks and knowing in fact very few about the ultimate construction, a fact recently studied by Aleksiev, Longdon, Christmas, Sendova-Franks and Franks (2007). Food collection, nest relocation, and brood caring are also complex social tasks collectively performed thanks to numerous simple, easy individual acts. This was, for instance, shown by Franks (1989) and examined 'under a novel look' by Langridge, Sendova-Franks and Franks (2008).

What occurs when ants are suddenly in never experienced situations? Let us examine and try to explain our results.

The ants could walk round a barrier. The nest entrance was visible through the glass forming the barrier; $M$. ruginodis workers have a visual perception of good quality and could thus see their nest entrance and its surroundings in the presence of a barrier. They thus acted just like when orienting themselves back to their nest. They knew the geography of at least some parts of their area, used memorized cues located on their way to their nest, remembered previous trajectories, and recognized their nest entrance. Finally, they perceived their nest entrance odor (Passera \& Aron, 2005). Such ability in navigating explains also the orientation of Cataglyphis velox workers towards their nest even when walking backwards for a time (Schwarz, Mangan, Zeil, Webb \& Wystrach, 2017). We presume that, on field, old workers can walk round an unexpected obstacle appearing on their way. During the present experiment, we observed that callow ants were helped by older nestmates, and that young ants imitated older ones.

Ants could use smooth substrates and avoid rough ones, but did not memorize such a choice. When coming back to their nest, ants deposit a trail; when going out of it, they lay down their Dufour gland content (Cammaerts-Tricot, 1974a). Doing so is probably very difficult on a rough substrate: the sting cannot touch continuously or periodically the substrate. Consequently, only the ants moving on the smooth substrates efficiently deposit the required pheromones. This may explain the more abundant traffic of ants on the smooth substrates. The ants' pheromones being volatile (Morgan, Tyler \& Cammaerts, 1977; Evershed, Morgan \& Cammaerts, 1981), all the process must begin anew in the course of a second trial.

Ants could establish a single way. As soon as an ant removed from its nest wanted to re-enter its nest, it walked on one path, and any ant wanting to go out of the nest had to walk on the other path. Such a phenomenon will amplify in the course of time. Moreover, the ants re-entering the nest deposit their trail pheromone while those going out of the nest lay down their Dufour gland content (Cammaerts-Tricot, 1974b). This soon renders the two paths different: one path with ants going in and an odor signifying 'way for going in'; another path with ants going out and an odor signifying 'way for going out'. The ants' traffic and the pheromonal deposits leaded thus to the establishment of a single way, in the same way as they lead to the use of one branch or of the two branches of a lozenge set on an ant linear traffic (Dussutour, Fourcassié, Helbing \& Deneubourg, 2004). We cannot explain why, for each colony, the left path was used for re-entering the nest, and the right path for going out of it. The ants removed from the nest were deposited exactly at the same place for each colony. They might have been deposited somewhat to the left of the nest entrance, and the ants wanting to re-enter their nest then preferentially used the left path. 
Some ants could push a 'door'. This behavior requires rather audacity than true cognition. It was performed by old experienced workers needing sugar water. No young ants was seen pushing the door, and ants coming out of the tube had an extended gaster, what proves they have drunk sugar water.

Finally, the results of our four experiments received a logic explanation and did not confer to ants exceptional cognitive abilities. Even if these abilities are spectacular and numerous (see 1), they are limited. The present and previous works allow stating that the ants' cognition includes 'self recognition, collective use of very simple methods, use of several informative social signals (i.e. words), always acting using hereditably acquired behavior', but probably excludes 'awareness, individual use of sensu stricto tools with memorization of such uses, use of an informative social language (i.e., sentences), ability of improvising novel acts in never experienced situations'. As a matter of fact, the ants' cognition is beyond solving simple problems requiring no new technology: the ants find the solution using their abilities in orienting, navigating, memorizing and communicating. This is in agreement with the statement of Hearly and Rowe (2010) that animals' cognition is based on various processing such as information gathering, memory, information retrieval and using information for decision making. In the four here examined situations, the cognitive process used by ants for solving the simple encountered problem has indeed required several abilities. Presently, our aim of defining the extent of the ants' cognition is not yet reached.

In a future work, we intend to examine if ants could spontaneously use or could learn to use novel methods through operant conditioning and imitation. Some ants were shown to be able to ameliorate a technique. The workers of Aphaenogaster subterranae and A. senilis, provided with honey solution and different materials allowing this honey collection, first use all the materials, then progressively select the best ones (Karath, 2016). This is not true cognition, but complex, progressive operant (instrumental) conditioning. Thereafter, we aim to examine if ants could use a tool, spontaneously, or could learn to use tools, progressively, step by step, through operant conditioning. Bumblebees can do so (Alem, Perry, Zhu, Loukola, Ingraham, 2016). The authors showed that 1) bumblebees ( Bombus terrestris) cannot or scarcely can pull a string for getting sugar water, 2) can learn this behavior if trained to perform it, in a stepwise manner, during a rather long time, 3) during such a acquisition, there are no 'insight' behavior, but only operant conditioning, 4) naïve bumblebees can acquire this complex behavior by seeing nesmates doing it. Note that, at a very sensu stricto point of view, the string proposed in these experiments was not a tool since it was already tied to the object to be pulled. Nevertheless, we shall examine if similar capabilities might also be detained by ants.

\section{Conclusion}

The workers of the ant M. ruginodis adequately behave in problematic situations (i.e. they can find a solution) as long as the problem can be solved without using new techniques (i.e. techniques which are not in the species behavioral repertory) or sensu stricto tools. They simply use their usual ability in orienting, navigating, communicating, and foraging. Future works will examine what occurs when other abilities (such as the use of a novel technique or a tool) are required.

\section{Acknowledgements}

We are very grateful to Dr Roger Cammaerts who corrected the paper and provided judicious advices for improving the figures.

\section{Ethical considerations}

We affirm having no conflict of interest at all concerning the present work on ants' cognition. The ants have been maintained in the laboratory under their best environmental conditions possible (temperature, light, electromagnetic field, food, water). The paper has never been published, nor submitted to another journal. The results are from us, and novel. All the informed researchers agree with our results.

\section{References}

Aleksiev, A. S., Longdon, B., Christmas, M. J., Sendova-Franks, A. B., \& Franks, N. R. (2007). Individual choice of building material for nest construction by worker ants and the collective outcome for their colony. Animal Behaviour, 74(3), 559-566. Retrieved from https://www.researchgate.net/../222674774_Individual_choice _of...

Alem, S., Perry, C. J., Zhu, X., Loukola, O. J., Ingraham, T., Sovik, E., \& Chittka, L. (2016). Associative mechanisms allow for social learning and cultural transmission of string pulling in an insect. PLoS Biology, 14(10), e 1002564. Retrieved from http://journals.plos.org/plosbiology/article?id=10.1371/journal.pbio... 
Cammaerts M.-C., Morel, F., Martino, F., \& Warzée, N. (2012). An easy and cheap software-based method to assess two-dimensional trajectory parameters. Belg. J. Zool., 142, 145-151. Retrieved from https://www.naturalsciences.be/en/BJZ

Cammaerts, M.-C. (2013a). Spatio-temporal learning in three Myrmica species (Hymenoptera, Formicidae). Bulletin de la Société Royale Belge d'Entomologie, 149, 131-138. Retrieved from www.srbe-kbve.be/sites/default/files/biblio_reprints_srbe_kbve.pdf

Cammaerts, M.-C. (2013b). Sensu stricto individual conditioning, and imitation, in the ant Myrmica sabuleti (Hymenoptera, Formicidae). Annales de la Société Entomologique de France, 49, 402-412. Retrieved from www.gallica.bnf.fr/ark:/12148/cb34349289k/date

Cammaerts, M.-C. (2017). Cognitive differences between conspecific ant colonies. Journal of Behavior, 2(1), 1005. Retrieved from https://www.jscimedcentral.com/Behavior/.../behavior-2-1005.pdf

Cammaerts, M.-C., \& Cammaerts, D. (2014). Comparative outlook over three Myrmica species' biotopes and foragers' know-how. Biologia, 69, 1051-1058. http://dx.doi.org/10.2478/s11756-014-0399-Z

Cammaerts, M.-C., \& Cammaerts, R. (2000). Nest odour in the ant Myrmica rubra (Myrmicinae). Biologia, 55, 509-523. Retrieved from www.serials.unibo.it/cgi-ser/start/en/.../ds-s.tcl?...Cammaerts\%2C...

Cammaerts, M.-C., \& Cammaerts, R. (2015a). Are ants (Hymenoptera, Formicidae) capable of self recognition? Journal of Sciences, 5(7), 521-532. Retrieved from www.journalofscience.net/File_Folder/521-532(jos).pdf

Cammaerts, M.-C., \& Cammaerts, R. (2015b). Ontogenesis of ants' cognitive abilities (Hymenoptera, Formicidae). Advanced Studies in Biology, 7, 335-348 + synopsis, 349-350. Retrieved from www.m-hikari.com/asb/asb2015/asb5-8-2015/index.html

Cammaerts, M.-C., \& Cammaerts, R. (2016a). Spatial expectation of food location in an ant on basis of previous food locations (Hymenoptera, Formicidae). J Ethology. http://dx.doi.org/10.1007/s10164-016-0494-4

Cammaerts, M.-C., \& Cammaerts, R. (2016b). Ants can expect the time of an event on basis of previous experiences. ISRN Entomology. Article ID 9473128, 9 p, http://dx.doi.org/org/10.1155/2016/9473128

Cammaerts-Tricot, M.-C. (1974a). Piste et phéromone attractive chez la fourmi Myrmica rubra. Journal of Comparative Physiology, 88, 373-382. http://dx.doi.org/10.1007/BF00694700

Cammaerts-Tricot, M.-C. (1974b). Recrutement d'ouvrières, chez Myrmica rubra, par les phéromones de l'appareil à venin. Behaviour L 1-2, 111-122. booksandjournals.brillonline.com > Journals > Behaviour

Dornhaus, A., \& Franks, N. R. (2008). Individual and collective cognition and other insects (Hymenoptera: Formicidae). Myrmecological News, 11, 215-226. Retrieved from www.chd.ucsd.edu/_files/fall2008/ Dornhaus.2008.MN.pdf

Dussutour. A., Fourcassié, V., Helbing, D., \& Deneubourg, J.-L. (2004). Optimal traffic organization in ants under crowded conditions. Nature, 428, 70-73. Retrieved from www.nature.com > Journal home > Archive > Letters to Nature

Evershed, R. P., Morgan, E. D., \& Cammaerts, M.-C. (1981). Identification of the trail pheromone of the ant Myrmica rubra L., and related species. Naturwissenschaften, 67, 374-385. Retrieved from www.jinsectscience.oxfordjournals.org/content/14/1/234.ref-stubs.xml

Franks, N. R. (1989). Army ants: A collective intelligence. American Scientist, 77, 139-145. Retrieved from www.citeulike.org/user/rincedd/article/1412810

Giurfa, M. (2013). Cognition with few neurons: higher-order learning in insects. Trends in neurosciences, 36(5), 285-294. Retrieved from www.scirp.org/.../reference/ReferencesPapers.aspx?ReferenceID...

Hearly, S. D., \& Rowe, C. (2010). Information processing: the ecology and evolution of cognitive abilities. In: Westneat DF, Fox CW, editors. Evolutionary behavioural ecology. Oxford: OUP.

Hölldobler, B., \& Wilson, E. O. (1990). The ants. Berlin, Springer Verlag. Retrieved from https://www.ncbi.nlm.nih.gov/pubmed/17811857

Jeanson, R., Deneubourg, J. L., Grimal, A., \& Theraulaz, G. (2004). Modulation of individual behavior and collective decision making during aggregation site selection by the ant Messor barbarus. Behavioral and Ecological Sociobiology, 55, 388-394. Retrieved from www.ulb.ac.be/sciences/use/publications/JLD/ 188.pdf 
Karath, K. (2016). Ants craft tiny sponges to dip into honey and carry it at home. Animal Behaviour. http://dx.doi.org/10.1016/j.anbehav 2016.11005.

Langridge, E. A., Sendova-Franks, A. B., \& Franks, N. R. (2008). How experienced individuals contribute to an improvement in collective performance in ants. Behavioral and Ecological Sociobiology, 62, 447-456. http://dx.doi.org/10.1007/s00265-007-0472-5 ...

Marsan, C., Simaon, M., Lavens, J., Chapelle, G., Saint Girons, S., Gérard, T. E., \& Julien, E. (2014). L'intelligence collective. Editions Yves-Michel. Retrieved from www.yvesmichel.org/product-page/ intelligence-collective/lintelligence-collective/

Martin, M., Chopard, B., \& Albuquerque, P. (2002). Formation of an ant cemetery: Swarm intelligence or statistical accident? Future Generation Computer Systems, 18(7), 951-959. Retrieved from https://www.researchgate.net/.../220284589_Formation_of_an_ant...

Morand-Ferron, J., Cole, E. F., \& Quinn, J. L. (2016). Studying the evolutionary ecology of cognition in the wild: a review of practical and conceptual challenges. Biological Reviews, 91, 367-389. Retrieved from onlinelibrary.wiley.com/doi/10.1111/brv.12174/full

Morgan, E. D., Tyler, R. C., \& Cammaerts, M.-C. (1977). Identification of the components of the Dufour's gland secretion of the ant Myrmica rubra L. and their behavioural responses. Journal of Insect Physiology, 23, 511-515. https://doi.org/10.1016/0022-1910(77)90262-1

Passera, L., \& Aron, S. (2005). Les fourmis: comportement, organisation sociale et évolution. Ottawa, Canada, Les Presses Scientifiques du CNRC. Retrieved from https://books.google.com/books/about/Les_fourmis. html?id=AVP_ts6LSVUC

Pasteels, J. M., \& Deneubourg, J.-L. (1987). From individual to collective behavior in social insects. Les Treilles Workshop /edited by Jacques M. Pasteels, Jean-Louis Deneubourg, Basel, Boston, Birkhäuser, 433 pp. Retrieved from www.nla.gov.au/anbd.bib-an5388628

Pearce, J. M. (2008). Animal learning and cognition, an introduction. East Sussex, USA, Canada, Psychology Press. Retrieved from https://www.amazon.co.uk/../Animal-Learning-Cognition-3rd-Intr...

Pfeiffer, K., \& Homberg, U. (2014). Organization and Functional Roles of the Central Complex in the Insect Brain. Annual Review of Entomology, 59, 165-184. http://dx.doi.org/10.1146/annurev-ento-011613-162031

Schwarz, S., Mangan, M., Zeil, J., Webb, B., \& Wystrach, A. (2017). How ants use vision when homing backward. Current Biology. http://dx.doi.org/10.1016/j.cub.2016.12.019

Siegel, S., \& Castellan, N. J. (1989). Nonparametric statistics for the behavioural sciences. Singapore, McGraw-Hill Book Company. Retrieved from https://www.amazon.com/Sidney -Siegel ...Statistics.../B008WDIR6...

Strausfeld, N. J. (1976). Atlas of an Insect Brain. Ed NJ Straufeld. Springer-Verlag publisher. ISBN: 978-3-642-66181-5 (Print) 978-3-642-66179-2 (Online). Retrieved from www.link.springer.com/book/10. 1007\%2F978-3-642-66179-2

Theraulaz, G., Bonabeau, E., Nicolis, S., Solé, R. V., Fourcassié, V., Blanco, S., ... Deneubourg, J. L. (2002). Spatial Patterns in Ant Colonies. Proceedings of the academy of Natural Sciences USA July 11. Retrieved from https://www.ncbi.nlm.nih.gov/pubmed/12114538

\section{Copyrights}

Copyright for this article is retained by the author(s), with first publication rights granted to the journal.

This is an open-access article distributed under the terms and conditions of the Creative Commons Attribution license (http://creativecommons.org/licenses/by/4.0/). 